\title{
Diabetes, glycemic control and risk of medical glaucoma treatment: A population-based case-control study
}

This article was published in the following Dove Press journal:

Clinical Epidemiology

12 November 2009

Number of times this article has been viewed

\author{
Lotte G Welinder' \\ Anders H Riis ${ }^{2}$ \\ Lars L Knudsen' \\ Reimar W Thomsen ${ }^{2}$ \\ 'Department of Ophthalmology, \\ ${ }^{2}$ Department of Clinical Epidemiology, \\ Aalborg Hospital, Aarhus University \\ Hospital, Aalborg, Denmark
}

Purpose: To examine the association between diabetes and risk of medical glaucoma treatment and to assess the role of long-term glycemic control in the putative association.

Design: Population-based case-control study.

Methods: Cases of treated glaucoma were all persons filling at least three prescriptions for glaucoma medication for the first time within one year between 2001 and 2006 in Northern Jutland, Denmark. We used risk set sampling to select 10 gender- and age-matched general population controls per case using the Danish Civil Registration System. Data on diabetes, comorbidities, and laboratory tests, including glycosylated hemoglobin (as a measure of glycemic control) were obtained from population-based medical registries. We calculated odds ratio (OR) as an estimate of relative risk for treated glaucoma comparing patients with and without diabetes, adjusted for comorbid conditions and medication use.

Results: We included 5,991 persons with incident medical glaucoma treatment and 59,910 population controls. The adjusted OR for treated glaucoma for patients with diabetes was 1.81 (95\% confidence interval: 1.65-1.98). The strength of the association between diabetes and glaucoma risk did not vary by diabetes duration or by the level of glycemic control.

Conclusions: Regardless of glycemic control, diabetes is associated with a substantially increased risk for medical glaucoma treatment.

Keywords: diabetes, glaucoma, glycemic control, prescriptions, population-based case-control study

\section{Introduction}

The morbidity, mortality and costs related to diabetes are escalating epidemically. A US citizen born in 2000 will have a 33\% lifetime risk of developing diabetes. ${ }^{1-3}$ Eye complications are important adverse effects of diabetes. Reduced intraocular blood flow in diabetic patients causes secondary nerve cell damage and leads to diabetic retinopathy. ${ }^{4}$ Diabetes may also cause a thicker central corneal thickness ${ }^{5}$ and a rise in intraocular pressure (IOP) $)^{6,7}$ made worse by poor long-term control of diabetes. ${ }^{6}$ Long-term control of diabetes can be assessed with measurements of glycosylated hemoglobin $\left(\mathrm{HbA}_{1 \mathrm{c}}\right) .8$

Glaucoma is the most common cause of irreversible blindness worldwide. ${ }^{10}$ The visual field loss in glaucoma caused by loss of retinal nerve cells can be worsened by nerve cell apoptosis, which is increased in diabetic patients. The previous epidemiologic studies that examined diabetes as a potential risk factor for glaucoma had conflicting conclusions. ${ }^{7,11-16}$ Moreover, while hyperglycemia is known to play a role in the development of diabetic retinopathy, to our knowledge no study has examined 
the association between the level of glycemic control and risk of glaucoma.

We hypothesized that diabetes is a risk factor for glaucoma, and that poor long-term glycemic control and longer duration of diabetes may increase the risk of glaucoma. We conducted a large case-control study using populationbased Danish medical databases.

\section{Methods}

We conducted the study in the former Danish counties of Northern Jutland and Aarhus, with a total population of 1.14 million mixed rural and urban inhabitants, representing $20 \%$ of the Danish population. ${ }^{17}$ The population is $93 \%$ Caucasian, and less than $2 \%$ migrate annually from or into the counties. ${ }^{17}$ The Danish National Health Service provides tax-financed primary medical care and free access to hospitals to all citizens. Furthermore, the National Health Service partially reimburses the costs of prescription medications, including those for glaucoma and diabetes. We linked data from several Danish population-based databases and medical registries. The unambiguous individual-level linkage is possible thanks to the Danish Civil Registration System, whereby a unique 10-digit civil registration number (CRN) encoding date of birth and sex is assigned to every Danish citizen at birth. The Civil Registration System ${ }^{18}$ was established in 1968. It is updated daily and tracks vital status, residence, and migrations. The CRN is used in all public databases to uniquely identify individuals. ${ }^{18}$

\section{Cases of medically treated glaucoma}

Glaucoma treatment cases were identified and categorized using the Danish National Registry of Patients (DNRP) ${ }^{19}$ and prescription databases of the two former counties merged into a research database at Aarhus University. Established in 1977, the DNRP tracks all hospitalizations and, from 1994 onwards, all outpatient visits. Recorded data include dates of admission and discharge, surgical procedures performed, and up to 20 diagnoses per visit or hospitalization. The diagnoses are coded by medical doctors using the 8 th revision of the International Classification of Diseases (ICD-8) through the end of 1993 and the 10th revision (ICD-10) thereafter. The prescription databases hold information on every sale of prescription medication in the counties, including date of dispensing and type of drug coded according to the Anatomical Therapeutic Chemical (ATC) classification system.

We defined an incident case of glaucoma treatment as a person filling three or more prescriptions for a glaucoma medication (ATC code group S01E) over 365 days or less during the study period, from January 1st, 2001 to December 31st, 2006. We required a minimum of three filled prescriptions on separate dates in order to exclude cases of possible shortterm secondary glaucoma associated with prior ocular surgery or uveitis. Glaucoma medication is sold only by prescription in Denmark and is prescribed for primary or secondary glaucoma or for ocular hypertension (OHT), but not for any other condition. We did not consider as cases patients with prescription for Acetazolamide tablets (ATC code S01 EC01), since these are used for other indications, including high-altitude sickness; moreover, they are rarely used for long-term glaucoma treatment. The date on which the patient filled his or her third prescription for a glaucoma medication was considered the glaucoma case index date. In order to be eligible for inclusion in the study, persons had to reside in one of the counties for at least five years before the index date. In order to only include patients with incident glaucoma, we excluded persons with prescriptions for a glaucoma medication filled within five years prior to the beginning of the study period and patients with a previous hospital contact with angle-closure glaucoma in the DNRP (ICD-10 diagnosis H40.2). We also excluded patients with glaucoma surgery or laser treatment prior to index date (procedure codes KCHD all, or KCHF 05-10-15-20-30 or 99, obtained from the DNRP). We identified incident glaucoma cases based on glaucoma medications rather than ICD-10 codes in our study because the majority of glaucoma patients in Denmark are treated in private practices that do not report diagnosis codes to the DNRP.

\section{Population controls}

Using data from the Civil Registration System to ascertain vital status and residence at the time of sampling, we randomly selected 10 population controls for each glaucoma case, matching birth-year, sex, and residence in one of the two counties for at least five years prior to the case's index date. Control selection was done by risk set sampling, ${ }^{20,21}$ whereby controls had to be alive and at risk of filling their third prescription for a glaucoma medication on the index date of their corresponding case. Odds ratios (OR) calculated from samples drawn using risk-set sampling provide estimates of the incidence rate ratio that would be observed in the underlying cohort. ${ }^{22}$ In this study OR was used as a measure of relative risk. The same eligibility and exclusion criteria were applied to cases and controls.

\section{Identification of diabetes}

Presence of diabetes for all subjects was ascertained by a validated method using prescription and hospital data. ${ }^{23}$ 
We used the DNRP to identify all persons with a hospitalization or outpatient diagnosis of diabetes mellitus recorded since 1977 (ICD-8 codes 249-250 and ICD-10 codes E10-14). From the counties' prescription databases we identified all persons with at least one prescription for insulin or an oral antidiabetic drug.

Diabetes was classified as type 1 diabetes mellitus (T1DM) for patients first diagnosed before the age of 30 years, treated with insulin monotherapy, and without history of taking an oral antidiabetic medication; the remaining diabetes patients were considered to have type 2 diabetes mellitus (T2DM). The use of insulin and oral antidiabetic medication was ascertained by selecting prescriptions with ATC codes A10A and $\mathrm{A} 10 \mathrm{~B}$ recorded in the prescription databases. ${ }^{23,24}$ Duration of diabetes was computed as the time elapsed from the first record of diabetes treatment or hospital diagnosis until the index date. Information on $\mathrm{HbA}_{1 \mathrm{c}}$ levels was obtained by linkage of the regional laboratory databases. ${ }^{25}$ These databases contain information on all specimens submitted for analysis by hospitals and practitioners, including the exact time of blood sample collection. The most recent measurement was used for analysis. We only could identify 27 T1DM patients in the case group; of these, 25 (93\%) had vitreoretinal surgery recorded before the index date, indicating secondary glaucoma. We refrained from making individual analysis on T1DM patients as this subgroup was too small and analyzed all diabetes patients together.

\section{Covariates}

We retrieved data on variables that are putative risk factors for glaucoma and also may be associated with diabetes. A recent review article identified cardiovascular events, hypertension, thyroid disease and migraine as risk factors for glaucoma. ${ }^{26} \mathrm{We}$ considered as potential confounders the following conditions, which were considered present if they were identified by a diagnosis in DNRP or by a relevant medication in the prescription database within five years prior to the index date for cases and matched controls: cardiovascular disease (ICD-10: E78; I20-26, 35.0-35.2, 60-61, 63-67, 69, 70, 74, 82), hypertension (ICD-10: I10-15), thyroid disease (ICD-10: E01-07, O90.5 and ATC: H03), migraine (ICD-10: G43 and ATC: N02C), autoimmune disorders (ICD-10: M05-9, M30-35, D86, K50-51, MO2.3, M45.9, M02.9, M03.2, M03.6, I73), alcoholism-related diagnoses (ICD-10: F10, K86.0, Z72.1, R78.0, T51, K 29.2, G62.1, G72.1, G31.2, I42.6), cataract (ICD-10: H25-26, 28.0 and procedure codes KCJA,C,D,E), retinal detachment (ICD-10: $\mathrm{H} 33.0$ and procedure codes KCKC60,70, KCKD25,30) and uveitis (ICD-10: H20, 22, 30, 32.0 and ATC-codes S01BA). Furthermore, we ascertained use of potential IOP-lowering systemic drugs: oral beta-adrenoceptor blockers (ATC: C07), statins (ATC: C10AA), and angiotensin-converting enzyme (ACE) inhibitors (ATC: C02E, C02L, C09A, C09B, C08DA51). ${ }^{27-30}$

\section{Statistical analysis}

We used conditional logistic regression to compute the crude and adjusted OR with 95\% confidence intervals (CI) for glaucoma according to presence of diabetes. Diabetes exposure was categorized by duration of diabetes ( $<5$ years, $\geq 5-<10$ years, $\geq 10$ years) and $\mathrm{HbA}_{1 \mathrm{c}}$ levels ( $<7 \%, \geq 7 \%-<8 \%, \geq 8 \%-<9 \%$, $\geq 9 \%$, unknown). ${ }^{8,31}$ We conducted analysis stratified by sex and age group: 0-50 years, 51-60 years, 61-70 years, 71-80 years, $81-90$ years, $>90$ years. We adjusted for cardiovascular disease, hypertension, thyroid disease, other autoimmune disorders, migraine, alcoholism-related disorders, and use of ACE inhibitors, beta-blockers, and statins. Analyses were conducted both with and without adjustment for retinal detachment, cataracts, and uveitis, as these conditions could represent intermediate steps between diabetes and development of glaucoma. All analyses were performed using Stata software (version 9.2; StataCorp, College Station, TX, USA).

\section{Results}

From January 1st, 2001 to December 31st, 2006, 9,295 patients filled at least one prescription for glaucoma medication in the counties' pharmacies; of these, 6,737 filled at least three prescriptions on different dates. Of these, 268 patients had more than 365 days between the first and the third glaucoma medication prescription, 384 patients moved away from the counties, and 94 patients had a history of angle-closure glaucoma or other glaucoma, laser treatment or surgery, and were therefore excluded, leaving 5,991 patients with medically treated incident glaucoma for analysis. Table 1 has descriptive data of the 5,991 cases with treated incident glaucoma and the 59,910 age- and sex-matched control subjects. Seven hundred and four patients using glaucoma medication had diabetes (11.8\%) compared with 3,975 $(6.6 \%)$ of the 59,910 controls. Patients using glaucoma medication were substantially more likely than controls to have a history of uveitis, cataract, and retinal detachment. Most other comorbidities and use of medications were slightly more prevalent among glaucoma cases than among matched controls (Table 1). 
Table I Adjusted and crude ORs for glaucoma according to presence of diabetes mellitus

\begin{tabular}{|c|c|c|c|c|}
\hline Risk factor & Cases & Controls & Crude OR $(95 \% \mathrm{Cl})$ & Adjusted OR ${ }^{a}(95 \% \mathrm{Cl})$ \\
\hline \multicolumn{5}{|l|}{ Sex } \\
\hline Male & $2,492(41.6)$ & $24,920(41.6)$ & & \\
\hline Female & $3,499(58.4)$ & $34,990(58.4)$ & & \\
\hline Age, years, median (IQR) & $70.4(60.8-78.4)$ & $70.3(60.8-78.4)$ & & \\
\hline \multicolumn{5}{|l|}{ Diabetes } \\
\hline Absent & $5,287(88.25)$ & 55,935 (93.37) & 1.0 (ref) & $\mathrm{I} .0$ (ref) \\
\hline Present & $704(11.75)$ & $3,975(6.63)$ & $1.95(1.79-2.12)$ & $1.81(1.65-1.98)$ \\
\hline Thyroid disease & $439(7.3)$ & $3,603(6.0)$ & $1.24(1.12-1.38)$ & $1.20(1.08-1.34)$ \\
\hline Migraine & $203(3.4)$ & $\mathrm{I}, 568(2.6)$ & $1.31(1.13-1.53)$ & $1.32(1.13-1.54)$ \\
\hline Auto immune disorders & $244(4.1)$ & $1,915(3.2)$ & $1.29(1.12-1.47)$ & $1.25(1.09-1.43)$ \\
\hline Cardiovascular risk factors & $765(12.8)$ & $7,919(\mid 3.2)$ & $0.96(0.88-1.04)$ & $0.76(0.70-0.84)$ \\
\hline Hypertension & $593(9.9)$ & $4,772(8.0)$ & $1.28(1.17-1.40)$ & $1.19(1.07-1.31)$ \\
\hline Alcohol related diagnoses & $47(0.8)$ & $494(0.8)$ & $0.95(0.70-1.29)$ & $0.91(0.68-1.24)$ \\
\hline ACE inhibitors & $\mathrm{I}, 042(\mathrm{I} 7.4)$ & $8,616(14.4)$ & $1.26(1.18-1.36)$ & $1.08(1.00-1.17)$ \\
\hline $\begin{array}{l}\text { Oral beta adrenoceptor } \\
\text { blockers }\end{array}$ & $1217(20.3)$ & II,695 (19.5) & $1.05(0.98-1.13)$ & $0.96(0.89-1.03)$ \\
\hline Statins & $828(13.8)$ & $6,307(10.5)$ & $1.05(0.98-1.13)$ & $1.29(I .|8-| .4 I)$ \\
\hline Cataract & $686(11.5)$ & $3,995(6.7)$ & $1.90(1.74-2.08)$ & $1.42(1.29-1.56)$ \\
\hline Retinal detachment & $135(2.3)$ & $159(0.3)$ & $8.65(6.86-10.90)$ & $6.15(4.82-7.85)$ \\
\hline Uveitis & $523(8.7)$ & I,349 (2.3) & $4.21(3.79-4.68)$ & $3.60(3.22-4.02)$ \\
\hline \multicolumn{5}{|l|}{ Duration of diabetes } \\
\hline Diabetes absent & $5,287(88.25)$ & $55,935(93.37)$ & I.0 (ref) & 1.0 (ref) \\
\hline$<5$ years & $320(5.34)$ & I,689 (2.82) & $1.88(1.66-2.14)$ & $2.03(1.79-2.29)$ \\
\hline$\geq 5-<10$ years & $200(3.34)$ & $1,210(2.02)$ & $1.64(1.41-1.92)$ & $1.77(1.52-2.06)$ \\
\hline$\geq 10$ years & $211(3.52)$ & I,III (I.85) & $1.87(1.60-2.18)$ & $2.02(1.74-2.35)$ \\
\hline \multicolumn{5}{|l|}{$\mathrm{HbA}_{\mathrm{lc}}$} \\
\hline Diabetes absent & $5,287(87.3)$ & $55,935(93.37)$ & I.0 (ref) & $\mathrm{I} .0$ (ref) \\
\hline $\mathrm{HbA}_{\mathrm{Ic}}<7 \%$ & $213(3.6)$ & $\mathrm{I}, 074(\mathrm{I} .79)$ & $1.97(1.69-2.30)$ & $2.12(1.83-2.47)$ \\
\hline $\mathrm{HbA}_{\mathrm{Ic}} \geq 7 \%-<8 \%$ & I50 (2.5) & $660(1.10)$ & $2.24(1.86-2.69)$ & $2.44(2.04-2.92)$ \\
\hline $\mathrm{HbA}_{\mathrm{Ic}} \geq 8 \%-<9 \%$ & $88(1.5)$ & $421(0.70)$ & $2.05(1.62-2.60)$ & $2.24(1.77-2.82)$ \\
\hline $\mathrm{HbA}_{\mathrm{Ic}} \geq 9 \%$ & $84(1.4)$ & $380(0.63)$ & $2.20(1.73-2.80)$ & $2.36(1.86-3.00)$ \\
\hline $\mathrm{HbA}_{\mathrm{Ic}}$ unknown & $196(3.3)$ & $\mathrm{I}, 475(2.46)$ & $1.34(1.15-1.57)$ & $1.41(1.21-1.65)$ \\
\hline
\end{tabular}

Notes: Data on cases and controls are $\mathrm{n}(\%) .{ }^{\mathrm{a}} \mathrm{OR}$ adjusted by conditional logistic regression for thyroid disease, migraine, autoimmune disorders, cardiovascular events, hypertension, alcohol-related disorders, angiotensin-converting enzyme inhibitors, oral beta adrenoceptor blockers and statins.

Abbreviations: $\mathrm{ACE}$, angiotensin-converting enzyme; $\mathrm{Cl}$, confidence interval; $\mathrm{HbA}_{\mathrm{lc}}$, glycosylated hemoglobin; $\mathrm{IQ}$, interquartile range; $\mathrm{OR}$, odds ratio.

The crude OR for using glaucoma medication in patients with diabetes was 1.95 (95\% CI: 1.79-2.12) (Table 1). After adjusting for confounding factors, the OR decreased slightly to 1.81 (95\% CI: $1.65-1.98)$. When the eye disorders of retinal detachment, cataracts, and uveitis were added to the model, the OR further decreased slightly, to 1.75 (95\% CI: $1.60-1.92)$.

One or more measurement of $\mathrm{HbA}_{1 \mathrm{c}}$ within the year prior to index date was available for 535 patients treated with glaucoma medication (73.3\%) with diabetes and for 2,535 of the controls $(63.0 \%)$ with diabetes. Diabetes was associated with about twofold increased risk for glaucoma at all levels of $\mathrm{HbA}_{1 \mathrm{c}}$ : adjusted ORs among diabetic subjects with an $\mathrm{HbA}_{1 \mathrm{c}}$ level of $<7 \%, \geq 7 \%-<8 \%, \geq 8 \%-<9 \%$, and $\geq 9 \%$ were 1.97 (95\% CI: 1.69-2.30), 2.24 (95\% CI: 1.86-2.69), 2.05 (95\% CI: $1.62-2.60)$, and 2.20 (95\% CI: 1.73-2.80), respectively (Table 1). Fifty-six percent of the diabetes patients who used glaucoma medication had had diabetes for more than five years. The duration of diabetes did not modify relative risk estimates considerably: $\mathrm{OR}=1.88$ (95\% CI: 1.66-2.14) for diabetes duration under five years, $\mathrm{OR}=1.64$ (95\% CI: 1.41-1.92) for duration between five 
and 10 years, and $\mathrm{OR}=1.87(95 \% \mathrm{CI}: 1.60-2.18, \mathrm{n}=200)$ for duration of more than 10 years.

The strength of association between diabetes and risk of using glaucoma medication decreased with age, with OR decreasing from 3.35 (95\% CI: 3.50-5.08) for patients aged 60 years or younger to 1.12 (95\% CI: $0.91-1.31)$ for patients older than 80 years. The effect of diabetes was greater among men with OR $=2.04(95 \%$ CI: 1.79-2.31) than among women with $\mathrm{OR}=1.61(95 \%$ CI: 1.42-1.83) (Table 2).

\section{Discussion}

We found that diabetes mellitus was associated with a 1.8-fold increased risk of medically treated glaucoma. The increased risk was independent of diabetes duration or of level of glycemic control. The relative effect associated with diabetes was greatest among persons aged under 60 years, possibly due to the lower baseline glaucoma risk in younger individuals. The effect was greater in men than in women.

The effect of diabetes on the risk of using glaucoma medication estimated in our study was similar to that estimated in the only other study of comparable size and design. In the Scottish Tayside study (2000), a cohort of all T2DM patients $(n=6,631)$ in the Tayside region was followed for two years between 1993 and 1995.32 The investigators used prescription data and operation codes as surrogate measures for glaucoma, while estimating, based on a case notes review, the extent of misclassification thus introduced. Based on 65 incident glaucoma cases in the T2DM cohort and 963 incident cases in the general Tayside population, relative risk was estimated at 1.57 (95\% CI: 0.99-2.48) for the association between T2DM and glaucoma. Four large cross-sectional studies found positive associations between

Table 2 Odds ratio (OR) for glaucoma according to presence of diabetes stratified by age and sex

\begin{tabular}{lll}
\hline & Crude OR $(95 \% \mathrm{Cl})$ & Adjusted OR $^{\mathrm{a}}(\mathbf{9 5 \%} \mathrm{Cl})$ \\
\hline Age & & \\
$0-60$ years & $4.22(3.50-5.08)$ & $3.35(2.72-4.14)$ \\
$61-70$ years & $2.55(2.17-2.99)$ & $2.26(1.90-2.69)$ \\
$71-80$ years & $1.54(1.32-1.79)$ & $1.47(1.25-1.73)$ \\
$>80$ years & $1.08(0.89-1.33)$ & $1.12(0.91-1.37)$ \\
Sex & & \\
Female & $1.74(1.54-1.96)$ & $1.61(1.42-1.83)$ \\
Male & $2.20(1.95-2.49)$ & $2.04(1.79-2.31)$ \\
\hline
\end{tabular}

Notes: a Odds ratio adjusted by conditional logistic regression for thyroid disease, migraine, autoimmune disorders, cardiovascular events, hypertension, alcohol related disorders, ace-inhibitors, oral beta adrenoceptor blockers and statins. Abbreviation: $\mathrm{Cl}$, confidence interval. diabetes and glaucoma including the Beaver Dam study $(1994 ;$ OR $=1.84 ; n=4,926$, glaucoma cases $=105) ;{ }^{11}$ the Rotterdam study $(1995 ;$ OR $=3.11 ; n=4,178$, glaucoma cases $=37){ }^{7}$ the Blue Mountain Eye study $(1997 ;$ OR $=2.12$; $\mathrm{n}=3,654$, glaucoma cases $=108) ;{ }^{12}$ and the Los Angeles Latino Eye Study (LALES, 2008; OR $=1.4 ; \mathrm{n}=5,894$, glaucoma cases $=288) \cdot{ }^{13}$ Other cross-sectional studies, including the Baltimore Eye Survey $(n=5,308$, glaucoma cases $=161)^{15}$ and the Ocular Hypertension Treatment Study $(\mathrm{n}=1,636 \text {, glaucoma cases }=119)^{14}$ showed no or even a negative association between diabetes and glaucoma. A meta-analysis that included most of the case-control and cross-sectional studies concluded that diabetes patients are at a significantly increased risk of glaucoma $(\mathrm{OR}=1.5$, 95\% CI: 1.16-1.93). ${ }^{33}$ Two recent prospective populationbased cohort studies found no association between diabetes and incident glaucoma: the Barbados Eye Study cohort $(\mathrm{n}=3,222$, glaucoma cases $=125$, OR diabetes $=1.2)$ was followed for nine years ${ }^{16}$ and the Rotterdam cohort $(n=3,387$, glaucoma cases $=87$, OR diabetes $=0.82$, was followed for seven years. ${ }^{34}$ In two subsequent letters, Ellis and Quigley propose that a potential surveillance bias in diabetic patients in previous studies may fully explain the apparent increased risk of glaucoma in diabetes patients. ${ }^{35,36}$ Our study is the first to demonstrate the equal risk of glaucoma associated with diabetes at all levels of glycemic control and duration of diabetes.

Our findings must be interpreted in the context of the study's methodological strengths and weaknesses. The universal health coverage of Denmark's national health care system enabled us to conduct a large, truly populationbased study, while using population-based data sources with independently and routinely recorded data. These features tend to reduce the risks of selection and information bias. As in previous studies of this issue, it is difficult to rule out surveillance bias stemming from greater likelihood of diabetic patients to undergo ophthalmological investigations compared with general population. ${ }^{11,32,34-36}$ As shown in the Beaver Dam study, diabetes patients with glaucoma were significantly more likely than glaucoma patients without diabetes to have consulted an ophthalmologist over a two-year period (49.2 vs 39.6\%). ${ }^{11}$ Some evidence for such bias in our data comes from the observation that glaucoma patients with diabetes tended to be slightly younger than other glaucoma patients (median age of 68.8 years vs. 71.1 years). Moreover, our case group is likely to include patients treated for OHT as in the Tayside Study. ${ }^{32}$ Our data did not allow us to differentiate primary from secondary glaucoma, neither 
could we differentiate between different types of glaucoma (pseudoexfoliation, angle closure, pigment dispersion, etc). Also, glaucoma diagnoses in this population-based study were made by approximately 60 different ophthalmologists who may have had different thresholds for commencement of medical treatment for glaucoma. Quigley and colleagues suggested that it is not safe to conclude that most physicians prescribe glaucoma medication according to preferred practice patterns, and that many patients fill their prescriptions so irregularly that they keep "reappearing" as incident glaucoma cases. ${ }^{37}$ We aimed to solve this potential problem with our defined medication algorithm.

Ascertainment of medication use and of data on covariates through independent administrative registries reduced potential patient-related (differential recall) or investigator-related information bias, which might affect studies with primary data collection. In order to become a glaucoma case in this study, patients had to buy glaucoma medication at least three different times within one year. These cases are very likely to actually use the medication and to have glaucoma rather than a temporary increase in IOP. Prescriptions can only be filled at a pharmacy, and all Danish pharmacies report complete data to the prescription database. Glaucoma medications purchased in pharmacies are partially refunded by the national health insurance, and the share of Internet-based or foreign purchases is negligibly small.

We were able to adjust our analysis for several potential confounders measured by data from the medical databases that aim to track complete prescription and medical history, including all surgical procedures performed. Known strong risk factors for glaucoma are older age, family history, and race. Hispanics ${ }^{13}$ and blacks ${ }^{16,38}$ are known to have a higher risk than Caucasians for both diabetes and glaucoma, but are hardly represented in this study performed in a very homogenous population of Caucasians. Most of the recently reviewed risk factors for glaucoma ${ }^{26}$ were more prevalent among cases than among controls in our study, but adjustment for their effects explained only $15 \%-20 \%$ of the observed diabetes effect. Of note, cardiovascular disease did not confound our analysis. While cardiovascular diseases and hypertension were associated with diabetes, they were equally prevalent among glaucoma cases and controls, which suggests that only a small part of the risk increase conferred by diabetes was mediated by these disorders.

In conclusion, our findings, representing the everyday practice pattern of Danish ophthalmologists, and based on a large population-based sample, corroborate and extend the existing evidence of diabetes mellitus as a risk factor for medical glaucoma treatment.

\section{Acknowledgments}

This study received financial support from Væm om Synet and from the Clinical Epidemiological Research Foundation at Aarhus University Hospital. The funding organization had no role in the design or conduct of this study.

\section{Disclosures}

The authors report no conflicts of interest in this work.

\section{References}

1. Harris MI, Flegal KM, Cowie CC, et al. Prevalence of diabetes, impaired fasting glucose, and impaired glucose tolerance in US adults. The Third National Health and Nutrition Examination Survey, 1988-1994. Diabetes Care. 1998;21:518-524.

2. Cheng D. Prevalence, predisposition and prevention of type II diabetes. Nutr Metab (Lond). 2005;2:29.

3. Narayan KM, Boyle JP, Thompson TJ, Sorensen SW, Williamson DF. Lifetime risk for diabetes mellitus in the United States. JAMA. 2003;290:1884-1890.

4. Barber AJ. A new view of diabetic retinopathy: a neurodegenerative disease of the eye. Prog Neuropsychopharmacol Biol Psychiatry. 2003;27:283-290.

5. Su DHW, Wong TY, Wong WL, et al. Diabetes, hyperglycemia, and central corneal thickness. The Singapore Malay Eye Study. Ophthalmology. 2008;115(6):964-968.

6. Oshitari T, Fujimoto N, Hanawa K, Adachi-Usami E. Effect of chronic hyperglycemia on intraocular pressure in patients with diabetes. $\mathrm{Am} \mathrm{J}$ Ophthalmol. 2007;143:363-365.

7. Dielemans I, de Jong PT, Stolk R, Vinerling JR, Grobbee DE, Hofman A. Primary open-angle glaucoma, intraocular pressure, and diabetes mellitus in the general elderly population. The Rotterdam Study. Ophthalmology. 1996;103:1271-1275.

8. Larsen ML, Horder M, Mogensen EF. Effect of long-term monitoring of glycosylated hemoglobin levels in insulin-dependent diabetes mellitus. N Engl J Med. 1990;323:1021-1025.

9. The effect of intensive treatment of diabetes on the development and progression of long-term complications in insulin-dependent diabetes mellitus. The Diabetes Control and Complications Trial Research Group. N Engl J Med. 1993;329:977-986.

10. Goldberg I. Relationship between intraocular pressure and preservation of visual field in glaucoma. Surv Ophthalmol. 2003;48(Suppl 1):S3-S7.

11. Klein BE, Klein R, Jensen SC. Open-angle glaucoma and older-onset diabetes. The Beaver Dam Eye Study. Ophthalmology. 1994;101: 1173-1177.

12. Mitchell P, Smith W, Chey T, Healey PR. Open-angle glaucoma and diabetes: the Blue Mountains eye study, Australia. Ophthalmology. 1997; 104:712-718.

13. Chopra V, Varma R, Francis BA, et al. Type 2 diabetes mellitus and the risk of open-angle glaucoma the Los Angeles Latino Eye Study. Ophthalmology. 2008;115:227-232.

14. Gordon MO, Beiser JA, Brandt JD, et al. The Ocular Hypertension Study. Arch Ophthalmol. 2002;714-720.

15. Tielsch JM, Katz J, Quigley HA, Javitt JC, Sommer A. Diabetes, intraocular pressure, and primary open-angle glaucoma in the Baltimore Eye Survey. Ophthalmology. 1995;102:48-53.

16. Leske MC, Wu SY, Hennis A, Honkanen R, NemesureB; BESs Study Group. Risk factors for incident open-angle glaucoma: the Barbados Eye Studies. Ophthalmology. 2008;115:85-93. 
17. Statistikbanken.dk. Denmarks statistikbank. Befolkning og Valg. Copenhagen, Denmark. Cited November 26, 2008. Available from: http://www.statistikbanken.dk/.

18. Pedersen CB, Gotzsche H, Moller JO, Mortensen PB. The Danish Civil Registration System. A cohort of eight million persons. Dan Med Bull. 2006;53:441-449.

19. Andersen TF, Madsen M, Jørgensen J, Mellemkjær L, Olsen JH. The Danish National Hospital Register. A valuable source of data for modern health sciences. Dan Med Bull. 1999;46:263-268.

20. Vestergaard P, Olsen ML, Johnsen SP, Rejnmark L, Sørensen HT, Mosekilde L. Corticosteroid use and risk of hip fracture: a populationbased case-control study in Denmark. J Intern Med. 2003;254:486-493.

21. Johnsen SP, Pedersen L, Friis S, et al. Nonaspirin nonsteroidal anti-inflammatory drugs and risk of hospitalization for intracerebral hemorrhage: a population-based case-control study. Stroke. 2003;34:387-391

22. Wacholder S, McLaughlin JK, Silverman DT, Mandel JS. Selection of controls in case-control studies. I. Principles. Am J Epidemiol. 1992;135:1019-1028.

23. Thomsen RW, Hundborg HH, Lervang HH, Johnsen SP, Sørensen HT, Schønheyder HC. Diabetes and outcome of community-acquired pneumococcal bacteremia: a 10-year population-based cohort study. Diabetes Care. 2004;27:70-76.

24. Thomsen RW, Hundborg HH, Lervang HH, Johnsen SP, Schønheyder HC, Sørensen HT. Risk of community-acquired pneumococcal bacteremia in patients with diabetes: a population-based case-control study. Diabetes Care. 2004;27:1143-1147.

25. Kornum JB, Thomsen RW, Riis A, et al. Diabetes, glycemic control, and risk of hospitalization with pneumonia: a population-based casecontrol study. Diabetes Care. 2008;31:1541-1545.

26. Pache M, Flammer J. A sick eye in a sick body? Systemic findings in patients with primary open-angle glaucoma. Surv Ophthalmol. 2006;51:179-212.

27. Hirooka K, Baba T, Fujimura T, Shiraga F. Prevention of visual field defect progression with angiotensin-converting enzyme inhibitor in eyes with normal-tension glaucoma. Am J Ophthalmol. 2006;142: 523-525.
28. Shah GB, Sharma S, Mehta AA, Goyal RK. Oculohypotensive effect of angiotensin-converting enzyme inhibitors in acute and chronic models of glaucoma. J Cardiovasc Pharmacol. 2000;36:169-175.

29. Costagliola C, Di Benedetto R, De Caprio L, Verde R, Mastropasqua L. Effect of oral captopril (SQ 14225) on intraocular pressure in man. Eur J Ophthalmol. 1995;5:19-25.

30. Suzuki R, Hanada M, Fujii H, Kurimoto S. Effects of orally administered beta-adrenergic blockers and calcium-channel blockers on the intraocular pressure of patients with treated hypertension. Ann Ophthalmol. 1992;24:220-223.

31. Mahmood K, Aamir AH. Glycemic control status in patients with type-2 diabetes. J Coll Physicians Surg Pak. 2005;15:323-325.

32. Ellis JD, Evans JM, Ruta DA, et al. Glaucoma incidence in an unselected cohort of diabetic patients: is diabetes mellitus a risk factor for glaucoma? DARTS/MEMO collaboration. Diabetes Audit and Research in Tayside Study. Medicines Monitoring Unit. Br J Ophthalmol. 2000;84:1218-1224

33. Bonovas S, Peponis V, Filioussi K. Diabetes mellitus as a risk factor for primary open-angle glaucoma: a meta-analysis. Diabet Med. 2004;21:609-614.

34. de Voogd S, Ikram MK, Wolfs RC, et al. Is diabetes mellitus a risk factor for open-angle glaucoma? The Rotterdam Study. Ophthalmology. 2006;113:1827-1831.

35. Ellis JD, Morris AD, MacEwen CJ. Should diabetic patients be screened for glaucoma? Br J Ophtalmol. 1999;83:369-372.

36. Quigley HA. Can diabetes be good for glaucoma? Why can't we believe our own eyes (or data)? Arch Opthalmol. 2009;127:227-229.

37. Quigley HA, Friedman DS, Hahn SR. Evaluation of practice patterns for the care of open-angle glaucoma compared with claims data Ophthalmology. 2007;114:1599-1606.

38. Brancati FL, Kao WH, Folsom AR, Watson RL, Szklo M. Incident type 2 diabetes mellitus in African American and white adults: the Atherosclerosis Risk in Communities Study. JAMA. 2000;283: 2253-2259.
Clinical Epidemiology

\section{Publish your work in this journal}

Clinical Epidemiology is an international, peer-reviewed, open access journal focusing on disease and drug epidemiology, identification of risk factors and screening procedures to develop optimal preventative initiatives and programs. Specific topics include: diagnosis, prognosis, treatment, screening, prevention, risk factor modification, systematic

\section{Dovepress}

reviews, risk \& safety of medical interventions, epidemiology \& biostatical methods, evaluation of guidelines, translational medicine, health policies \& economic evaluations. The manuscript management system is completely online and includes a very quick and fair peerreview system, which is all easy to use. 